rewarming process to see the heart begin to contract and continue the circulation, the patient returning to normal within a matter of minutes following the operation, a patient who, judged by our old standards, had apparently been dead for up to one hour. Yet this is exactly what happens, and many chronic invalids owe to these procedures not only restoration to almost normality but also prolongation of life.

\section{The Future}

So much for past history. What of the future ? Only a bold man would try to forecast the shape of things to come. It would be foolish to suggest that surgery has now reached its zenith. Already certain lines of advance are evident. Grafting of tissues and organs has been performed. Corneal grafting is an outstanding example, and one of the past presidents of this Association, Tudor Thomas, made no small contribution to its success. There have been satisfactory organ grafts, especially in identical twins, and once the immune response to the grafted organ is overcome who can forecast the operation's future? There are bound to be problems, and not only immunological and bacteriological ones. Moral and ethical questions inevitably follow in the train of such operations.

But one thing can be safely predicted: the coming 50 years will be as exciting and rewarding for those engaged in surgery as has been the last half-century.

\title{
Incidence of Suicidal Attempts in an Urban Community
}

\author{
D. PARKIN,* M.B., D.P.M. ; E. STENGEL, $†$ M.D., F.R.C.P.
}

Brit. med. F., 1965, 2, 133-138

The incidence of suicidal attempts is difficult to establish. Attempted suicide is not a diagnosis and therefore does not appear in the diagnostic index of hospital records. Usually the type of intoxication or the physical or mental condition which led to the suicidal attempt is entered, without reference to the latter. It is true that the International Classification of Diseases, Injuries and Causes of Death has a category of suicidal poisoning and injuries, but, in this country at least, it is hardly ever used. Therefore no reliable statistical data concerning the incidence of suicidal attempts are available, even among hospital admissions. When attempted suicide was still an indictable offence in this country, the number of cases known to the police did not usually exceed those of suicides. They were obviously only a fraction of the attempts committed. Their real incidence is of considerable interest for the clinician and the epidemiologist. People who have attempted suicide are more likely to kill themselves later on than people who have no such history (Stengel and Cook, 1958). They form a highly vulnerable part of the population. Also, suicidal attempts present medical and psychiatric emergencies, and it would be important to know what claims they can be expected to make on the hospital services. Finally, their incidence and its fluctuations in a population may be indicators of mental or social disorders which may not necessarily be identical with those resulting in suicide.

The purpose of this study was to establish the incidence of suicidal attempts-that is, of non-fatal suicidal acts-in the City of Sheffield, which has a population of slightly under half a million, for the years 1960 and 1961. The following definition of a suicidal attempt was adopted. "A suicidal attempt is any act of self-damage undertaken with the apparent intention of self-destruction, however half-hearted and ineffective. The patient may have been only vaguely aware of his intention, which sometimes has to be inferred from his behaviour" (Stengel, 1963). This definition is in practice identical with the operational definition adopted by Kessel and Lee (1962), who included all cases of self-inflicted overdose, gassing, or injury admitted to the observation ward where they carried out the:r study.

\footnotetext{
* Consultant Psychiatrist, King's Mill Hospital, Mansfield, Notts ; lately Senior Registrar, Department of Psychiatry, United Sheffield Hos-
pitals, and Middlewood Hospital, Sheffield.

$\dagger$ Professor of Psychiatry, University of Sheffield ; Honorary Consultant Psychiatrist, United Sheffield Hospitals and Middlewood Hospital,
Sheffield.
}

\section{Methods of Inquiry}

The total number of suicidal attempts can be divided into four groups of persons: (1) those seen in the casualty departments, out-patient clinics, and wards of general hospitals ; (2) those admitted to a mental hospital ; (3) those seen by doctors in their surgeries or at home; and (4) people who made a suicidal attempt without a doctor being called in. The size of group 4 is not ascertainable. However, its existence can be inferred from occasional reports of such attempts given by patients and sometimes confirmed by witnesses months or years after the event. The number of such attempts is probably small but not negligible.

The possibility of those attempting suicide being admitted to private nursing-homes, which were not included in this survey, was considered. From inquiries among doctors in Sheffield it appeared most unlikely that such cases were admitted to those homes, most of which were not equipped for emergencies.

The size of the third group-that is, of those seen by general practitioners first-can be established only by a special survey. The first two groups-that is, the hospital admissions, are not easy to ascertain either, for reasons mentioned above.

One and the same suicidal attempt is apt to be included in more than one group, with consequent double or treble entry. To avoid such cases being counted more than once, a register was drawn up, and for every case traced the following particulars were recorded wherever possible : name, address, date of attempt, sex, age, marital status, source of information, mode of attempt, length of stay in hospital and subsequent disposal, and name of patient's regular doctor.

\section{Suicidal Attempts Seen in General Hospitals}

A total of over 160,000 casualty entries in the three general hospitals serving the city were checked through by one of us (D. P.), the cards of the attempts being sorted out. This survey was preceded by a scrutiny of a sample month in the casualty department of each of the three hospitals. As a rule it was easy to pick out suicidal attempts from the records. Most suicidal overdosages and gassings were apparent as such. Almost all cases of cut throat were suicidal, while many cut wrists were clearly accidental. It was found that the following types of entry in the casualty card served as indications for closer study of the casualty to which it referred: (a) no diagnosis, $(b)$ collapse, (c) coma, $(d)$ head injury, $(e)$ laceration of throat and wrist, $(f)$ stab wound, $(g)$ poisonings of all kinds. Suicidal attempts were almost invariably
recognized as such by the casualty officers. 
Most cases of attempted suicide came direct to the casualty department, being brought by relatives, police, ambulance, or general practitioner. A psychiatrist is always on call, and patients not admitted to a ward are seen by him before being sent home, usually under the care of a relative. Many are referred to the psychiatric out-patient department for early attention. The majority of these cases seen in the casualty departments were admitted to medical and a few to surgical wards of the three general hospitals (see under Results). Some were admitted to the psychiatric departments of these hospitals direct from the casualty departments. Others were transferred to these departments after the state of medical or surgical emergency had subsided. There are two general hospitals with psychiatric departments in Sheffieldthey are the Royal Infirmary, which belongs to the teaching hospital group (United Sheffield Hospitals), and the City General Hospital. The former has a 38-bed psychiatric department to which a day hospital with 20 places is attached. The City General Hospital has a 12-bed psychiatric department.

In the psychiatric department of the Royal Infirmary a simple questionary is filled in for every new in-patient and out-patient. One group of questions refers to suicidal attempts:

Suicidal attempt.

(a) recent-i.e., related to present admission ( )

(b) history of previous suicidal attempts..... ( )

\section{Patients Admitted to the Mental Hospital}

Middlewood Hospital (2,050 beds) is the mental hospital serving the city of Sheffield (population about 500,000) and an equal population of South Yorkshire. As the routine case-notes were not reliable enough to serve as a source of retrospective information, it was decided to study a sample of current admissions with the help of a questionary similar to the one employed at the psychiatric department of the teaching hospital.

All consecutive admissions to Middlewood Hospital from 16 March to 14 September 1962 were scrutinized specifically for suicidal attempts associated with that admission.

\section{General-practitioner Survey}

All general practitioners on the list of the National Health Service, who looked after $98 \%$ of the population, were sent the letter and questionary reproduced below (see Appendix) in January 1961 and 1962 referring to the preceding years. The questionary had to be brief and easy to complete. Experience in this country has shown that any research inquiry more complicated and more demanding of doctors' time than this one was unlikely to meet with a satisfactory response. It had to be made clear to the doctors that they were not expected to go through their records, although they were not discouraged from doing so. A suicidal attempt was thought to be a sufficiently rare and dramatic event in the doctor's work to stay in his memory. The doctors were not asked to give particulars about their patients who had made suicidal attempts. It seemed important to assure them that the patients could not be identified.

The second question in the questionary (How many patients did you suspect of having made a suicidal attempt ?) needs some explanation. It is a common experience that doctors not versed in psychiatry and unfamiliar with the suicide problem tend to classify among suicidal attempts only those patients who admit suicidal intention. These doctors are inclined to accept the patients' assurance that they did not intend to kill themselves, though their behaviour may have indicated this. The experienced psychiatrist, when seeing such patients in hospital, does not find it difficult to elicit suicidal intention from them, or at least the feeling that "they did not care whether they lived or died." Many, perhaps most, suicidal attempts are carried out in such a mood (Stengel, 1963). These cases are, of course, included among those attempting suicide seen in hospital. They are likely to be excluded by the general practitioner who is requested to state the number of attempts he has encountered in a certain period. He would, however, readily include them among those he suspected of having made a suicidal attempt. Question 2 was aimed at these cases, who otherwise might have been lost. A discussion with a group of general practitioners about the inquiry suggested that the inclusion of this question served the intended purpose.
It was not regarded as necessary to include specialists in this survey. Having discussed the matter with consultant physicians and surgeons practising in the city, and having made special inquiries among patients, we were satisfied that specialists are hardly ever called upon to intervene in the patients' homes in cases of attempted suicide. If a consultant should be the first to appear on the scene he has to inform the patient's general practitioner, even if the patient has to be removed to hospital without delay. In this case the patient's name would appear among the list of suicidal attempts seen in hospitals. In this country the omission of specialists from a survey of suicidal attempts seen by doctors practising outside hospitals is unlikely to result in a loss of relevant cases.

\section{Results}

\section{General Hospital Survey}

Table I shows the numbers of cases of attempted suicide seen in the general hosp:tals of the city during 1960 and 1961. About $15 \%$ were resident outside the city boundary. Almost $4 \%$ made two attempts within a year. Particulars of the civil status were available for only two-thirds of the patients. They had not always been recorded on the casualty cards.

\begin{tabular}{|c|c|c|c|c|c|c|c|}
\hline \multirow[b]{2}{*}{ Year } & \multirow{2}{*}{ Total } & \multicolumn{2}{|c|}{ Residence } & \multirow[b]{2}{*}{ Male } & \multirow[b]{2}{*}{ Female } & \multirow{2}{*}{$\begin{array}{l}\text { Second } \\
\text { Attempt }\end{array}$} & \multirow{2}{*}{$\begin{array}{l}\text { Three } \\
\text { or More } \\
\text { Attempts }\end{array}$} \\
\hline & & $\begin{array}{c}\text { In } \\
\text { City }\end{array}$ & $\begin{array}{c}\text { Else- } \\
\text { where }\end{array}$ & & & & \\
\hline $\begin{array}{l}1960 \\
1961\end{array}$ & $\begin{array}{l}330 \\
331\end{array}$ & $\begin{array}{l}280 \\
279\end{array}$ & $\begin{array}{l}50 \\
52\end{array}$ & $\begin{array}{l}125 \\
113\end{array}$ & $\begin{array}{l}205 \\
218\end{array}$ & $\begin{array}{l}13 \\
12\end{array}$ & $\begin{array}{l}1 \\
2\end{array}$ \\
\hline
\end{tabular}

Table II presents the number of cases seen in the various departments and referrals to other hospitals and social agencies. The second column concerns patients referred back to their doctors from the casualty department. Some of those seen in the psychiatric out-patient clinic were admitted to a psychiatric ward in the general hospital. The "chronic hospitals" mentioned in the table were geriatric and other wards for chronic physical diseases. "Other agencies" were the social services of the city, probation officers, the regiment, the university, Marriage Guidance Council, etc. There was considerable overlap of the various categories listed in Table II.

TABLE II.-Numbers of Cases of Suicidal Attempts Seen in Various Departments of General Hospital. Transfers to Other Hospitals

\begin{tabular}{|c|c|c|c|c|c|c|c|}
\hline Year & 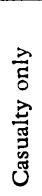 & 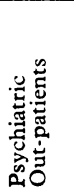 & 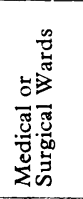 & 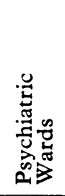 & 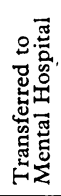 & 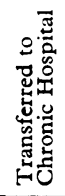 & 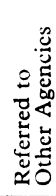 \\
\hline $\begin{array}{l}1960 \\
1961\end{array}$ & $\begin{array}{l}32 \\
38\end{array}$ & $\begin{array}{l}135 \\
149\end{array}$ & $\begin{array}{l}269 \\
256\end{array}$ & $\begin{array}{l}85 \\
59\end{array}$ & $\begin{array}{l}39 \\
52\end{array}$ & $\begin{array}{l}5 \\
6\end{array}$ & $\begin{array}{l}25 \\
30\end{array}$ \\
\hline
\end{tabular}

The average length of stay in the general hospital wards was 6.3 days for 1960 and 5.5 days for 1961. Only two patients were noted as having taken their discharge against medical advice. Almost all the patients admitted to the medical and surgical wards after a suicidal attempt were seen by a psychiatrist, who advised about further psychiatric treatment and/or referral to social agencies.

In the psychiatric department of the teaching hospital $10 \%$ of all new admissions were associated with suicidal attempts. These patients stayed three weeks on the average, which was 10 days less than the average stay of the in-patients in these wards. The length of out-patient treatment varied. Onequarter of the patients referred to the psychiatric out-patient clinic after a suicidal attempt attended only once ; $5 \%$ were still attending after three years, the remainder having attended once or twice monthly for up to two years. One-third of all these patients terminated treatment at their own request or by repeated failure to attend. 


\section{Mental Hospital}

Of the 920 patients admitted to the Middlewood Hospital during the six months surveyed 135 had made suicidal attempts associated with their admission : $42(31.1 \%)$ came from within the city boundary but only 14 of them came from home; the rest came v.a another hospital in the city. In contrast, about one-half of all admissions came from the city. This discrepancy was probably due to the fact that a larger proportion of suicidal attempts committed within the city than of those occurring in the surrounding area is dealt with by the Sheffield general hospital services.

The male: female ratio among the attempted suicides was $5: 8$, which corresponded to the sex ratio of the whole population of th's hosiptal. Of the patients admitted after suicidal attempts $60 \%$ were of the short-stay category-that is, they were in hospital 28 days or less-the average length of stay being 13 days ; $40 \%$ stayed from 1 to 10 months, the average being 2 months. These figures reflected the policy of the hospital, which favours early discharge whenever possible. Of the cases of suicidal attempt admitted from the city two-thirds came from the general hospitals, the rest came from their homes via their doctors or the mental welfare officers after attempts not resulting in medical or surgical emergencies.

If one assumes the figures for the six months surveyed to be representative of the whole year, the total number of cases of suicidal attempt annually admitted to this mental hospital direct from home was estimated to have been 28 . The number recorded as received from general hospitals in the city-that is, 28 for six months-tallied with the number of those recorded as transferred from the latter hospitals to the mental hospital during that period. The total number of patients resident in Sheffield and admitted to th:s mental hospital after suicidal attempts in the course of a year can therefore be estimated to have been 84 .

\section{General-practitioner Survey}

In $1960164(62.5 \%)$ out of 258 questionaries were returned and in $1961181(69.1 \%)$ out of 260 (Table III). The cases were considered under two headings-those referred to hospital and those treated at home. The accuracy of the former figure could be verified to some extent by cross-checking with the hospital records, which usually contained the doctors' names.

TABLE III.-General-practitioner Survey. Figures in Parentheses are the Estimated Totals for all Doctors to Whom the Questionary was Sent

\begin{tabular}{|c|c|c|c|c|c|c|}
\hline \multirow[b]{2}{*}{ Year } & \multicolumn{2}{|c|}{ Questionaries } & \multirow{2}{*}{$\begin{array}{l}\text { Attempts } \\
\text { Recorded }\end{array}$} & \multirow{2}{*}{$\begin{array}{l}\text { No. per } \\
\text { Dostor }\end{array}$} & \multirow{2}{*}{$\begin{array}{l}\text { Treated } \\
\text { at Home }\end{array}$} & \multirow{2}{*}{$\begin{array}{l}\text { Sent to } \\
\text { Hospital }\end{array}$} \\
\hline & $\begin{array}{l}\text { No. } \\
\text { Sent }\end{array}$ & $\begin{array}{c}\text { No. } \\
\text { Returned }\end{array}$ & & & & \\
\hline $\begin{array}{l}1960 \\
1961\end{array}$ & $\begin{array}{l}258 \\
260\end{array}$ & $\begin{array}{l}164 \\
181\end{array}$ & $\begin{array}{l}191(299) \\
151(216)\end{array}$ & $\begin{array}{l}1 \cdot 16 \\
0.83\end{array}$ & $\begin{array}{l}40(62) \\
35(41)\end{array}$ & $\begin{array}{l}151(237) \\
116(166)\end{array}$ \\
\hline
\end{tabular}

Table IV shows the number of attempted suicides reported by individual general practitioners. The percentage of practitioners who had not seen an attempt was $43 \%$ in 1960 and $41 \%$ in 1961 . The same practices did not report identical returns in each of the two years. Only 16 of the doctors who returned both questionaries had not seen a case in either year.

TABLE IV.-Number of Cases of Attempted Suicide seen by Individual

\begin{tabular}{c|c|c|c|c|c|c}
\hline Year & Nil & 1 & 2 & 3 & 4 & $\begin{array}{c}5 \text { or } \\
\text { More }\end{array}$ \\
\hline 1960 & 70 & 36 & 36 & 13 & 5 & 3 \\
1961 & 74 & 29 & 26 & 12 & 4 & 3 \\
\hline
\end{tabular}

The number of suicidal attempts reported by general practitioners as referred to hospital was lower than the number of those seen in hospital (Tables I and III) when the former figures were corrected for the non-respondents among the doctors. There was a fairly good correspondence between individual practice returns of attempted suicides and practice names taken from hospital case papers, although again the practitioners' figures tended to be lower.

The discrepancy between the hospital figures and those reported as referred to hospital can be accounted for by the following factors: (a) failure on the part of the general practit:oner to record or remember cases seen ; $(b)$ doctors may have tended to report only those attempts in which they intervened and not those of which they had been informed by hospitals or relatives ; and (c) patients coming to hospital without their general practitioner being informed. There is evidence that the last-mentioned happens occasionally. Relatives sometimes rush a patient to the casualty department, and if he is dealt with quickly and discharged the general practitioner may not always be informed by the casualty officer. Sometimes the patient and his relative would make the request that no report be sent to the family doctor. Some patients seen in hospital may not be on a local doctor's list, or may deny that they are.

Table III shows that the proportion of cases reported as seen but not referred to hospital was $21 \%$ in 1960 and $23 \%$ in 1961 . If these proportions are representative for all general practitioners, including the non-respondents, the number of cases which can be assumed to have been seen in general practice but not referred to hospital would be 62 for 1960 and 41 for 1961 . The number of cases seen yearly by a general practitioner was 1.16 in 1960 and 0.83 in 1961, which would give a total number of cases of suic:dal attempt seen by all practitioners to whom a questionary was sent of 299 in 1960 and 216 in 1961 .

Is it reasonable to assume that the practitioners returning and those not returning the forms saw a similar number of cases of attempted suicide proportionately ? Judging from the numbers from the non-responders' clienteles which were seen in hospital this is a reasonable assumption. The nonresponders were proportionally represented among the doctors of the patients seen in hospital following suicidal attempts. This could be established because every hospital patient is asked the name of his general practitioner, who could be identified by us as either a responder or non-responder. Table III column 7 shows the estimated total of patients referred to hospital by local general practitioners, including those who had not returned the questionary.

There is no way of checking the proportion of cases of attempted suicide seen by the non-responding practitioners and not referred by them to hospital, but it is unlikely that they differed in this respect from their colleagues who co-operated in this inquiry. The estimated figures for this category are given in parentheses in Table III, column 6.

The reason for the inclusion of question 2 concerning suspected suicidal attempts and the explanation why it was decided to count those cases as suicidal attempts are given above. It seemed of interest to find out, so far as this was possible with the questionary used, whether it was the suspected cases who were not sent to hospital by their doctors. If this had been so the justification for including them among the suicidal attempts could be questioned. Table $\mathrm{V}$ shows the size of the categories of definite and suspected attempts reported, as well as the number of those not sent to hospital by their doctors. (Those not entered into the latter group had obviously been sent to hospital.) The numbers in parentheses refer to the repeat attempts. It is noteworthy that among the 47 suspected attempts reported for the two years there was only $1(2.2 \%)$ repeated attempt, compared with $37(11.6 \%)$

TABlE V.-Attempts and Suspected Attempts. Repeat Attempts in \begin{tabular}{c|c|c|c} 
& \multicolumn{3}{|c}{ Parentheses } \\
\hline Year & Attempts & Suspected & Treated at Home \\
\hline 1960 & $169(20)$ & $22(1)$ & $40(2)$ \\
1961 & $126(17)$ & 25 & 35 \\
\hline
\end{tabular} 
among the 295 definite attempts. This suggests that a history of a previous attempt tended to dispel doubts about the suicidal character of the act. The fact that of the total of 75 attempts treated at home during the two years only $2(2.6 \%)$ were repeat attempts indicates that if there was a history of a previous attempt the patient was almost invariably sent to hospital.

The questionary did not ask what action the doctor took in individual cases, but this information could be obtained from a considerable proportion of questionaries-that is, from those in which the number of cases reported belonged to one category only (either to the attempted suicides or to the suspects), and the same number had either been sent to hospital or had been treated at home. For instance, if a practitioner had seen one case only of an attempt, or a suspected attempt, and reported having dealt with one case without referral to hospital, this could refer only to the case reported. If, however, he reported that he had seen one definite and one suspected case, and stated that one case had been dealt with at home, it was impossible to know which of the two this was. These cases are classified under " unknown" in Table VI, in which the attempts treated at home are divided into attempts and suspected attempts. In view of the large number of the unknown it is impossible to say what proportion of the suspects were dealt with at home. It can only be said that many of them were sent to hospital and that the majority of those treated at home had been diagnosed as suicidal attempts.

Table VI.-Attempts and Suspected Attempts Not Sent to Hospital

\begin{tabular}{c|c|c|c|c}
\hline Year & $\begin{array}{c}\text { No. Treated } \\
\text { at Home }\end{array}$ & Attempts & Suspected & Unknown \\
\hline 1960 & 40 & 24 & 6 & 12 \\
1961 & 35 & 22 & 2 & 9
\end{tabular}

\section{Total Number of Suicidal Attempts}

The estimated total number of suicidal attempts consists of the four groups mentioned under Methods of Inquiry. There was no way of assessing the fourth group-that is, those not seen by a doctor. Table VII shows the size of the first three groups, which do not overlap because care was taken not to include a case in more than one group. This is why the cases seen in the general hospitals form by far the largest group.

\begin{tabular}{|c|c|c|c|c|c|c|}
\hline TABLE & $\begin{array}{l}\text { VII.-Estim } \\
\text { Suicides Co }\end{array}$ & $\begin{array}{l}\text { ed Total } \\
\text { mitted in }\end{array}$ & $\begin{array}{l}\text { Numbers } \\
\text { Sheffield }\end{array}$ & $\begin{array}{c}\text { of Suic } \\
\text { During } 1\end{array}$ & $\begin{array}{l}\text { Attem } \\
0 \text { and } 1\end{array}$ & ${ }_{51}^{t s}$ and \\
\hline Year & $\begin{array}{l}\text { Group } 1 \\
\text { General } \\
\text { Hospital }\end{array}$ & $\begin{array}{c}\text { Group } 2 \\
\text { Mental } \\
\text { Hospital }\end{array}$ & $\begin{array}{l}\text { Group } 3 \\
\text { Treated } \\
\text { at Home }\end{array}$ & $\begin{array}{c}\text { Total } \\
\text { No. of } \\
\text { Attempts }\end{array}$ & Suicides & $\begin{array}{c}\text { Ratio } \\
\text { Attempts/ } \\
\text { Suicides }\end{array}$ \\
\hline $\begin{array}{l}1960 \\
1961 \\
\text { Total }\end{array}$ & $\begin{array}{l}330 \\
331 \\
661\end{array}$ & $\begin{array}{l}28 \\
23 \\
56\end{array}$ & $\begin{array}{r}62 \\
41 \\
103\end{array}$ & $\begin{array}{l}420 \\
400 \\
820\end{array}$ & $\begin{array}{l}39 \\
47 \\
84\end{array}$ & $\begin{array}{r}10 \cdot 7 / 1 \\
8 \cdot 5 / 1 \\
9 \cdot 7 / 1\end{array}$ \\
\hline
\end{tabular}

The estimated total number of 420 suicidal attempts for 1960 compared with 39 suicides in the same year. In 1961 the ratio was $400: 47$. The incidence of suicidal attempts was respectively 10.7 and 8.5 times that of the suicides, and it was 9.7 times for both years together. As the size of the fourth group -that is, that of attempts not seen by a doctor-is unknown, and as some cases must have been missed in both the hospital and the general-practitioner surveys, the actual number of attempted suicides can be presumed to have been bigger than that found in this survey.

\section{Statistical Data}

Data concerning methods of self-injury, sex and age distribution, etc., were available for most of the cases seen in hospital. The records of those seen in the casualty departments and not admitted were sometimes incomplete. No particulars of the cases seen by general practitioners and not sent to hospitals were available, for reasons stated above. It cannot be taken for granted that the patients about whom the data were available were representative of the rest.

Table VIII compares the methods used in the suicidal attempts admitted to hospital with those used in the fatal suicidal acts during the two years.

TABLE VIII.-Methods of Self-damage Used (percentages)

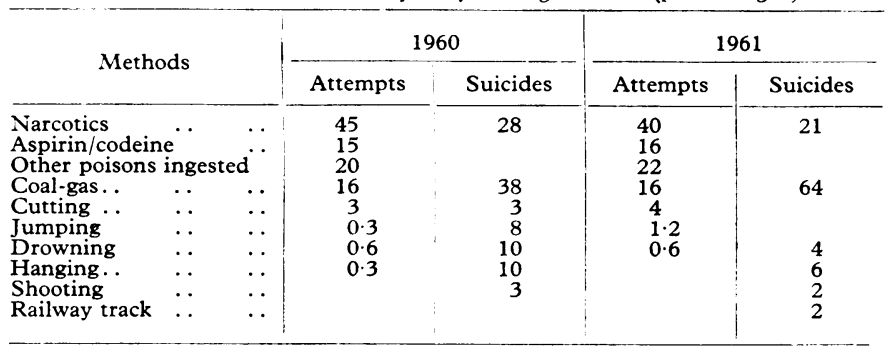

Table IX shows the sex distribution among the cases of suicidal attempt admitted to hospital and among the suicides. The figures for suicidal attempts are incomplete. The striking difference between the sex ratio of suicides registered in the two years is not a freak observation. It is in keeping with the increase of the female suicide rate which has been a general trend since the beginning of this century. Stengel and Cook (1958), in a comparative study of the suicide rates of two cities in the North of England, found that in one of the two cities the female rate was higher than the male rate.

TABle IX.-Sex Distribution Among Cases of Attempted Suicide Admitted to Hospitals and Among Suicides

\begin{tabular}{|c|c|c|c|c|c|c|}
\hline & & & \multicolumn{2}{|c|}{1960} & \multicolumn{2}{|c|}{1961} \\
\hline & & & Attempts & Suicides & Attempts & Suicides \\
\hline $\begin{array}{l}\text { Male } \\
\text { Female }\end{array}$ & $\begin{array}{l}\cdots \\
\cdots\end{array}$ & $\begin{array}{l}\cdots \\
\cdots\end{array}$ & $\begin{array}{l}122 \\
198\end{array}$ & $\begin{array}{l}26 \\
13\end{array}$ & $\begin{array}{l}111 \\
208\end{array}$ & $\begin{array}{l}21 \\
26\end{array}$ \\
\hline Total & . & . & 320 & 39 & 319 & 47 \\
\hline
\end{tabular}

The number of cases seen in the general hospitals fluctuated from month to month. In 1960 the months with the highest numbers of admission were April (36), August (35), November (36), and December (39). In 1961 the peak months were April (40), June (34), and December (31). The following were the totals for the 12 months of both years put together: 41 , $53,55,76,49,58,40,53,56,54,56,75$.

Table $\mathrm{X}$ shows the representation of the various age groups among the attempted suicides seen in hospitals and among the suicides registered in the coroner's court. The age group " under 20 " consisted only of persons admitted to wards for adults-that is, not below the age of 15 . Children's wards were not included in this inquiry. The table shows that up to the age of 50 the ratio between non-fatal and fatal suicidal acts was very high, though it declined with every decade. In the two years under survey there had been only one suicide under the age of 30 in Sheffield. After the age of 50 the ratio was between $5: 1$ and $2.8: 1$.

TABlE X.-Age and Sex Distribution of 639 Attempted Suicides.

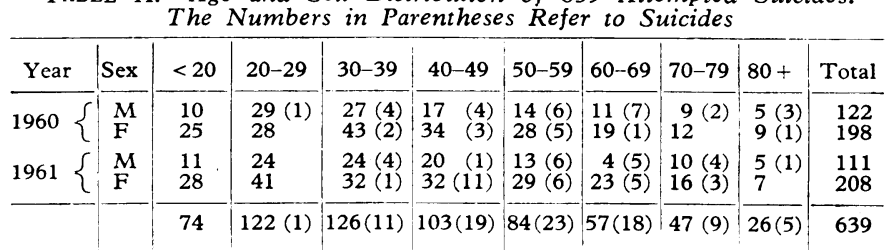

\section{Discussion}

This investigation aimed at no more than establishing the approximate incidence of suicidal attempts in an urban 
community. Accordingly, the scope of the questionary sent to family doctors was very limited. More information could have been asked for, but it was felt, rightly or wrongly, that the response to a fuller questionary might be unsatisfactory. It is intended to ask for a few more data in future inquiries.

The only comparable inquiry so far reported in the literature is the one carried out by the Los Angeles Suicide Prevention Center and reported by Farberow and Shneidman (1961). They searched hospital records and circulated letters among all physicians, including specialists, asking them whether and how many suicidal attempts they had encountered in their practices. For each case reported they sent a questionary concerning age, sex, religion, and other data relevant to suicide statistics. The average number of attempts seen by each physician at Los Angeles was 2.24. The ratio of attempted to committed suicides was approximately $8: 1$ in 1957 , rather similar to that found in this investigation. The two cities differed in their suicide rates considerably. At Los Angeles it was 14, at Sheffield 7.8 in 1960 and 9.4 in 1961 . The report of the Los Angeles survey makes no special reference to the proportion of cases of attempted suicide seen by doctors but not sent to hospital.

A number of published surveys include only hospital admissions, but not an inquiry among doctors working outside hospitals. Rüegsegger (1963), for example, confined himself to the cases admitted to hospital in Basle in 1954 and 1959. He was confident that all those who attempted suicide were admitted to hospital. The ratio of attempts to suicides was between $10: 1$ and $15: 1$. Similar surveys were carried out by James et al. (1963) at Perth, Western Australia, where the ratio between attempted suicides seen in hospital and suicides was $88: 12$, and more recently at Leicester, England, where the ratio was similar to the one found at Basle. There is no reason to doubt that in those cities, too, a sizable proportion of suicidal attempts was dealt with by doctors in the patients' homes without referral to hospital. The fact that even without them the ratios between attempts and suicides found at Basle and Leicester were higher than at Sheffield may be due either to the Sheffield figures being underestimates or to their being genuinely lower than in the other two cities. The former explanation seems the more likely one, because in a retrospective inquiry a number of cases are usually missed.

The exclusion of children's wards from the hospital inquiry is unlikely to have caused a substantial inaccuracy. There was no case of suicide among children under 15 in Sheffield during the two years under survey. The paediatricians in charge of the two children's departments serving the city estimated the total number of suicidal attempts seen by them as below 10 per annum. As the questionary used in the generalpractitioners' survey did not ask about the patient's age, it is not impossible that a small number of children were among the cases reported.

Some of the findings of this survey may reflect local conditions. For instance, the relation between suicidal attempts admitted to the various hospitals may be different in other cities. Even the proportion of cases dealt with by their doctors at home may vary according to the availability of hospital beds in a locality. With regard to the sex ratio, age distribution, and use of methods of self-damage the population surveyed in this investigation did not differ from groups reported elsewhere. Because the various data were not available about all of them, and because it is far from certain that those about whom they were available were representative of the whole group, generalizations have to be tentative and provisional. The most important finding of this survey is the considerable number of suicidal attempts not seen in hospital. All the cases in which life seemed to be in danger were no doubt sent to hosp:tal, but not all cases in which there was no physical emergency were dealt with at home. Whether or not a suicidal attempt results in admission to hospital depends on a variety of factors additional to the degree of self-damage (Stengel and

Cook, 1958). The inclusion of the cases described by their family doctors as suspected attempts was vindicated by their being diagnosed as definite attempts if they were admitted to hospital.

In the two years surveyed in this study the suicide rates differed considerably, and so did the number of suicidal attempts: this was smaller in the second year, when the number of suicides was higher. No general conclusions concerning the relations between attempts and suicide can be drawn from this small sample, and indeed from any sample, unless the incidence of suicidal attempts can be established with reasonable reliability.

\section{Summary}

An investigation into the incidence of suicidal attempts which had occurred in an urban population of about half a million within two years has been carried out.

The number of attempts which had led to admission to the general and mental hospitals serving the population was established and the number of attempts seen by general practitioners was estimated with the help of a questionary.

About one in five cases of attempted suicide seen in the patients' homes by their doctors were not sent to hospital.

The ratio between suicidal attempts and suicide was found to have been 10.7:1 in the first year and 8.5:1 in the second year. The ratio for both years together was $9.7: 1$.

There were reasons for assuming that the figures for suicidal attempts found in this survey were underestimates.

Dear Doctor,

\section{Appendix}

\section{Suicidal Attempts in Sheffield during 1961}

We are writing to enlist your help in an inquiry into attempted suicides in Sheffield, which is the first investigation of its kind carried out in this country.

While the number of suicides is known, we have no knowledge of the incidence of suicidal attempts. The number of those admitted to hospitals in Sheffield should be available to us, but some suicidal attempts are satisfactorily dealt with at home by general practitioners. Without your help, therefore, we cannot arrive at an estimate of the real incidence. We are concerned with total incidence only, not with individual patients of individual doctors.

We should be most grateful if you would fill in the attached questionary and return it to us in the enclosed stamped addressed envelope. Kindly do so, even if you should not have encountered any cases of this type during the last year. You might not find it necessary to consult your records, because these cases are few and are likely to stand out in your memory. The questionary asks about patien:s as well as attempts, because some patients make more than

\section{QUESTIONARY}

Attempted Suicides

1. How many of your patients made suicidal attempts during the last year?

2. How many patients did you suspect of having made a suicidal attempt? (Not to be included under 1)

3. With how many cases of this type did you deal without referral to hospital ?

4. For partnership practices: these figures include: (a) Number of patients

(b) Number of attempts

(z) Number of patients

(b) Number of attempts

(.) Numier of patien:s

(b) Number of attempis $\ldots \ldots \ldots \ldots$

(a) All cases from the whole partnership.

(b) Patients on my own list only. ( $\checkmark$ where applicable)

Signed 
one attempt within a year. Please include all relevant cases, irrespective of whether or not they were admitted to hospital. Do not include "successful" attempts with fatal outcome.

It is sometimes difficult to distinguish between a suicidal threat or gesture and a suicidal attempt. The latter should be defined as any act of self-damage undertaken with the apparent intention of self-destruction, however half-hearted and ineffective. The patient may have been only vaguely aware of this intention, which sometimes has to be inferred from his actions. The degree of actual danger to life, as seen from our point of view, is not relevant for inclusion in this group ; many attempts which to us seem harmless are undertaken with serious intent, and vice versa. The questionary has a category for doubtful cases.
We should be glad to answer any questions you might wish to ask us.

Thanking you for your co-operation, Yours sincerely,

REFERENCES

Farberow, N. L., and Shneidman, E. S. (1961). The Cry for Help. McGraw-Hill, New York.

James, I. P., Derham, S. P., and Scott-Orr, D. N. (1963). Med. F. Aust., 1, 375.

Kessel, N., and Lee, E. M. (1962). Scot, med. 7., 7, 130.

Rüegsegger, P. (1963). Psychiat. et Neurol. (Basel), 146, 81

Rüegsegger, P. (1963). Psychiat.
Stengel, E. (1963). Lancet, 1, 233.

and Cook, N. G. (1958). Attempted Suicide. Chapman and Hall, London.

\title{
A Controlled Therapeutic Trial of Various Diets in Ulcerative Colitis
}

\author{
RALPH WRIGHT,* M.D., D.PHIL., M.R.C.P. ; S. C. TRUELOVE,* M.D., F.R.C.P.
}

Brit. med. F., 1965, 2, 138-141

Andresen (1925) was the first to suggest that ulcerative colitis might be due to food allergy. He continued to study the disease in this light and later reported that in two-thirds of his patients one or more specific items of the diet appeared to be the principal aetiological factor in the disease, with cow's milk as the most important, while others were wheat, tomatoes, oranges, potatoes, and eggs (Andresen, 1942). Closely similar conclusions were reached by Rowe (1942).

Since then there have been occasional reports of apparent allergy to milk or other foods in patients with ulcerative colitis (Sarles et al., 1959 ; Rider et al., 1960). However, the difficulty in assessing the value of eliminating a particular food from the diet in a disease in which remissions and relapses are variable and unpredictable has made this contention difficult to prove.

Our own interest in this possibility arose when a small group of patients with ulcerative colitis who had become symptom-free on a milk-free diet all relapsed when milk was reintroduced into the diet (Truelove, 1961). By taking into account the average relapse rate in ulcerative colitis it was estimated that the odds were more than 1,000 to 1 against this run of relapses after challenge being due to chance. Although this finding strongly suggests that milk may be a factor in the aetiology of ulcerative colitis so far as some patients are concerned, it does not provide proof.

It seemed essential to test the therapeutic value of a milk-free diet in ulcerative colitis under more stringent conditions than in previous studies. We have therefore made a controlled clinical trial of various diets in this disease. In view of the findings of Taylor and Truelove (1961) that patients with ulcerative colitis are more likely than normal subjects to have high titres of circulating antibodies to two of the purified proteins of cow's milk, the immunological reactions to several dietary proteins have been studied in parallel.

The results of the clinical study are now presented. The immunological findings are only mentioned briefly, as they are being reported in detail separately (Wright and Truelove, 1965).

\section{Experimental Design}

Patients presenting with an attack of ulcerative colitis were allocated at random to one of three dietary groups: (a) a milk-

* Nuffield Department of Clinical Medicine, the Radcliffe Infirmary, Ox́ord. free diet ; (b) a gluten-free plus milk-free diet ; and (c) a control group on a "dummy" diet.

A stratified design was used to ensure a close balance between the three dietary groups. The patients were divided into those seen during the first attack and those seen during a relapse of established disease. The patients in relapse were further divided into those patients with a short history, of less than three years; those with a medium history, of three to 10 years; and those with a long history, of 10 years or more. Patients in each of these clinical categories were allotted at random to the dietary groups, employing restricted randomization to keep the numbers in the three dietary groups approximately equal.

\section{Selection of Patients}

All patients, whether in-patients or out-patients, seen during an attack of ulcerative colitis confirmed by sigmoidoscopy and barium enema examination, were admitted to the trial, provided that: (a) they were prepared to keep to a strict diet for a period of one year and to attend for follow-up at monthly intervals ; (b) they had not already been on treatment with corticosteroids for the attack for more than one week; and (c) no major complication of ulcerative colitis was present.

\section{Non-dietary Treatment}

In addition to the diet all patients were given a standard course of medical treatment with prednisolone by mouth in a dose of $5 \mathrm{mg}$. six-hourly for six weeks and hydrocortisone hemisuccinate $100 \mathrm{mg}$. nightly by rectal infusion for two months, together with any general medical measures necessary for the particular case. If the attack was severe enough to warrant admission to hospital the dose of prednisolone was doubled and the rectal infusion used twice daily. All patients were given two tablets of Omnivite Forte for the period of the trial. A similar course of treatment was given for each relapse (as defined below) during the trial period.

\section{Dietary Treatment}

At the time of admission to the trial the patient was told the nature of the diet in general terms and was then referred to a dietitian, who explained it in more detail. A diet sheet was 